\title{
PROPOSIÇÕES COTIDIANAS PARA A ESCOLA EM CRISE. QUAL $O$ LUGAR DA DIVERSIDADE CONTEMPORÂNEA?
}

\author{
DAILY PROPOSITIONS FOR SCHOOL IN CRISIS. WHAT IS THE PLACE OF \\ CONTEMPORARY DIVERSITY?
}

\section{PROPUESTAS DIARIAS PARA ESCUELA EN CRISIS. ¿CUÁL ES EL LUGAR DE LA DIVERSIDAD CONTEMPORÁNEA?}

Adelmar Santos de Araújo1

Géssica Ferreira da Silva²

\section{RESUMO}

O presente artigo é resultado de uma pesquisa em andamento realizada numa escola de ensino médio e fundamental da rede pública de educação do Estado de Goiás. Partiu-se, inicialmente, do levantamento bibliográfico para, em seguida, realizar o confronto analítico-relacional teoria e prática e contribuir com debate acerca da diversidade na escola contemporânea. Consta-se que não basta analisar a crise na educação ou na escola apenas com parâmetros relacionados à diversidade em si. É necessário ir além, e compreender a dinâmica da escola e da diversidade no âmbito da crise do atual modelo de sociedade.

PALAVRAS-CHAVE: Educação e antropologia, Influência do professor, Diversidade, Papel da escola, Crise na educação escolar.

\section{ABSTRACT}

The present article is the result of an ongoing research carried out in a high school and elementary school in the public education network of the State of Goiás. Initially, the bibliographic survey was started, and then the analytical-relational confrontation between theory and practice and contribute to debate about diversity in contemporary school. It is said that it is not enough to analyze the crisis in education or school only with parameters related to diversity itself. It is necessary to go further, and understand the dynamics of the school and diversity in the context of the crisis of the current model of society.

KEYWORDS: Education and anthropology, Teacher influence, Diversity, Role of the school, Crisis in school education.

\footnotetext{
${ }^{1}$ Historiador e Mestre em Educação pela Universidade Federal de Goiás, UFG. Doutor em Educação pela Pontifícia Universidade Católica de Goiás - PUC-GO.

2 Graduada em Ecologia e Análise Ambiental pela Universidade Federal de Goiás - UFG. Fez complementação pedagógica em Licenciatura Biologia pela faculdade Campus Elíseos. Atua como professora de Ciências, do ensino fundamental, na unidade pública do Colégio Estadual Horácia Lobo.
} 


\section{RESUMEN}

Este artículo es el resultado de una investigación en curso llevada a cabo en una escuela secundaria y primaria en la red de educación pública del Estado de Goiás. Inicialmente, se inició la encuesta bibliográfica, y luego la confrontación analítico-relacional entre la teoría y practicar y contribuir al debate sobre la diversidad en la escuela contemporánea. Se dice que no es suficiente analizar la crisis en la educación o en la escuela solo con parámetros relacionados con la diversidad misma. Es necesario ir más allá y comprender la dinámica de la escuela y la diversidad en el contexto de la crisis del modelo actual de sociedad.

PALABRAS CLAVE: Educación y antropología, linfluencia docente, Diversidad, Papel de la escuela, Crisis en la educación escolar.

\section{Introdução}

"Proposições cotidianas para a escola em crise. Qual o lugar da diversidade contemporânea?" é resultado de parte do levantamento bibliográfico de uma pesquisa a ser realizada em uma escola da rede pública de educação do Estado de Goiás.

Nossa experiência em sala de aula levou-nos a constatar o quão distante estamos de romper as barreiras em relação à diversidade "de toda ordem" presente na escola.

O texto está dividido em duas seções. Na primeira, discutiu-se possibilidades de pensar dialogicamente educação e antropologia; na segunda parte, buscou-se compreender a relação entre políticas educacionais e diversidade social no Brasil atual.

\section{Pensar dialogicamente educação e antropologia}

Para entender a crise e sua pluralidade no âmbito escolar, antes, é necessário estabelecer um diálogo entre a educação e a antropologia, que muito pode contribuir para o nosso presente.

Segundo Gusmão (1997),

É necessário que se adentre no pensamento antropológico, em suas bases epistemológicas como ciência e como ciência aplicada, com seus alinhamentos teóricos, avanços e limites. Aqui parece residir a importância do passado para nosso presente, pois somente nesse percurso parece ser possivel vencer uma certa instrumentalização da antropologia pela educação, propiciadora de muitos equívocos, e onde, certamente, se terá, como ganho, a superação de estigmas e preconceitos que grassam de ambos os lados 
dessa fronteira ou desse divisor de águas - a antropologia como ciência, a pedagogia como prática.

A antropologia permite refletir os mecanismos de formação e de práticas de professores/educadores perante sociedades multiculturais como a nossa. A relação entre elas abre espaço para um debate, reflexão e intervenção, que acolhe desde o contexto cultural da aprendizagem, os efeitos sobre a diferença cultural, racial, étnica e de gênero, até os sucessos e insucessos do sistema escolar em face de uma ordem social em mudança (GUSMÃO, 1997).

A pluralidade cultural, apesar de toda sua riqueza, não tem tido espaço na sociedade, que, muitas vezes, discrimina sua diversidade, fazendo com que esta seja desrespeitada na cultura brasileira, que é formada por uma miscigenação de etnias. A base para viver democraticamente, é respeitar os diferentes grupos. Isto deveria ser notório no ambiente escolar, que promove a formação do indivíduo. Todavia, o público escolar não tem demonstrado compreensão, e o grande desafio é investir na superação da discriminação. (Brasil, 1997, apud VALENTE, 2003, p. 32).

Para Valente (2003) parece pouco provável que a escola se posicione criticamente em relação à história como uma concepção moralista que descole a exploração e dominação de certos grupos humanos do contexto em que ocorreram e/ou foram refuncionalizados para justificar a desigualdade. $\mathrm{O}$ que hoje aparece como errado, pode não ter sido nas épocas passadas. $\mathrm{A}$ solução estaria na construção de ações que resultem na compreensão dos mecanismos históricos, resgatando a historicidade dos significados que a diversidade assume (VALENTE, 2003, p. 39).

Nesta discussão da pluralidade cultural, o pragmatismo utópico se manifesta, o qual denota a ideia de que, as críticas dirigidas à sociedade permanecem fora dos muros da escola (VALENTE, 2003, p. 39). Pensamento este, surreal, uma vez que, os estudantes convivem diariamente com as desigualdades sociais, e a escola não está isenta deles, uma vez que ela é composta por indivíduos componentes da sociedade.

Para Lopes da Silva e Grupioni, (1995), a antropologia parece não estar acessível ao público. Seus estudos acerca da pluralidade cultural poderiam auxiliar na desconstrução de preconceitos. Todavia, ela não consegue se comunicar com os profissionais da educação, que, ao modificarem a linguagem, para que esta seja mais acessível ao público, acaba não esclarecendo e promovendo interpretações mecanicistas (LOPES DA SILVA E GRUPIONI, 1995 apud VALENTE, 2003, p. 24/25).

Para Valente (2003), há uma contradição na definição de escola como espaço para diálogo, vivências e descobertas, uma vez que, esta, se apresenta de forma histórica e 
hegemonicamente, um espaço de imposição, monólogo, certezas, coabitações. Desse modo, antes de transformar a educação é necessário transformar a sociedade.

Se é verdade que a escola é um espaço de convivência entre crianças e adolescentes de diferentes origens, de transmissão dos conhecimentos sistematizados sobre o país e o mundo e um dos lugares onde são ensinadas as regras do espaço público, isso não significa necessariamente que essas promovam o convívio democrático com a diferença. Ao contrário, ali podem ser ensinadas as regras do espaço público marcadas historicamente pelo desrespeito a diferença: como se fosse possível que a crítica dirigida a sociedade permanecesse fora dos muros da escola; como se a desigualdade, a injustiça, os conflitos de classe e de cultura existentes na sociedade, de alguma maneira, fosse neutralizada no contexto escolar, que se tornaria, desse modo, uma realidade a-histórica. (VALENTE, 2003, p.30).

A discriminação cultural se apresenta de diversas faces, contudo, o preconceito racial ainda sobressai nas discussões contemporâneas, apesar de ser considerado crime. Fica evidente que alguns grupos estão mais expostos à exclusão social que outros, e não se pode perder estas características históricas que favorecem a discriminação (VALENTE, 2003, p. 31).

Diante de toda essa discussão, não se pode responsabilizar a formação dos professores, uma vez que o conhecimento sobre a pluralidade cultural ainda não é acessível. (VALENTE, 2003, p. 32).

Tratar-se-á de garantir que todas as crianças sejam o público alvo da proposta educativa sobre a pluralidade cultural e de impedir que seja construída uma preocupação centrada na diferença do outro, especialmente porque se insiste no texto que diferentes grupos encontraram "[...] maneiras de preservar sua identidade cultural". (Brasil, 1997 apud VALENTE, 2003 p.32).

A antropologia pressupõe que

[...] é errado, conceitual e eticamente, sustentar argumentos de ordem racial/ética para justificar desigualdades socioeconômicas, dominação, abuso, exploração de certos grupos humanos. Historicamente, no Brasil, tentou-se justificar, por essa via, injustiças cometidas contra povos indígenas, contra africanos e seus descendentes, desde a barbárie da escravidão a formas contemporâneas de discriminação e exclusão destes e de outros grupos étnicos e culturais, em diferentes graus e formas. A escola deve posicionar criticamente mediante estes fatos, mediante informações corretas, cooperando no esforço histórico de superação do racismo e da discriminação. (Brasil, 1997 apud VALENTE, 2003 p. 39).

Diante de todo o contexto discutido, as influências europeias de um universo monocultural dificultam a contenção da discriminação racial, onde, apenas a cultura dominante tem direito a 
expressar-se. Na sociedade em que vivemos, com tamanha diversidade de culturas, a educação deveria ser em uma ótica pluricultural, possibilitando a livre expressão de todos os povos. (VALENTE, 2003, p.42).

O professor tem grande influência na transposição de informação e tem o poder de recuperar e ensinar as crianças, o respeito mútuo entre as diferentes culturas. Porém, observa-se na sociedade, uma interpretação errônea das culturas, onde as diferentes etnias são tratadas homogeneamente, como no caso do poema do índio citado por Gusmão (2003), que retrata que a escola ensina de forma desrespeitosa que, todos os povos indígenas, podem ser resumidos em índios, desconsiderando toda a sua história cultural e diversificação de grupos. (GUSMÃO, 2003, p.88).

Em um ambiente heterogêneo "o que está em jogo é a diferença do outro e a sua identidade, que exige que se abdique daquilo que se é para assumir a identidade do eu como modelo a ser imitado. O eu nesse caso, é o branco, ocidental, cristão [...] superior". (GUSMÃO, 2003, p.88).

Todo esse conflito de identidade será discutido e aperfeiçoado na escola, que deverá ser o local de harmonia e aceitação do eu e do outro, como enfatiza Gusmão (2003), no seguinte questionamento.

Como então fazer do outro um mesmo, transitar pelo seu mundo e ele pelo nosso, sem confronto, sem conflitos, sem fazer dele um igual para melhor submetê-lo? Como conviver com as diferenças e estabelecer relações solidárias e de equidade entre sujeitos diferentes? Esses são os desafios permanentes da educação e da escola. (GUSMÃO, 2003, p.89).

A diferença tem significado em nosso país, quase sempre como desigualdade. Isto atribui uma interpretação errônea, sendo que, para solucionar as diferenças, a proposta seria a igualdade. E isto, seria inapropriado em um país com tamanha heterogeneidade cultural. (Santos, 1989 apud GUSMÃO, 2003, p. 90).

[...] Fazemos parte de uma sociedade de classes em que as relações sociais entre sujeitos são relações de hierarquia e poder, que se sustentam em classificações dadas a priori e "naturalizadas" como próprias deste ou daquele grupo - Sebastião é negro porque tem nariz chato e cabelo "ruim" / os índios são selvagens ou preguiçosos. [...] a dificuldade de aprender é explicada pelo fato de ser "[...] paraibano, nordestino, favelado, vesgo, canhoto, filho de prostituta [...]" (Santos, 1989 apud GUSMÃO, 2003, p. 92). 
Educar não é uma tarefa fácil, e na maioria das vezes, ela está em um embate entre interesses, dominação, exploração, revelando o poder e seu exercício sobre os indivíduos. 0 diferente segue no processo educativo até se tornar igual ao modelo de educação proposto. (GUSMÃO, 2003, p. 93).

É comum ouvir o relato de professores que todos os alunos são tratados de forma igual naquela escola. Excluir as diferenças parece contraditório, visto que há uma pluralidade em suas origens, histórias e modo de vida. No ponto de vista citado, todos são colocados em um "saco" e tratados de forma homogênea, desprezando sua cultura. (GUSMÃO, 2003, p. 93).

Para solucionar os problemas da diversidade social e cultural, nem a igualdade absoluta, nem a diferença relativa são adequadas. É na escola que todos terão, mediante o convívio, a sociabilização (GUSMÃO, 2003, p.94).

[...] A escola como espaço sociocultural é entendida, portanto, como um espaço social próprio, ordenado em dupla dimensão. Institucionalmente, por um conjunto de normas e de regras, que buscam unificar e delimitar a ação de seus sujeitos. Cotidianamente, por uma complexa trama de relações sociais entre sujeitos envolvidos, que incluem alianças e conflitos, imposições de normas e estratégias individuais de apropriação constante dos espaços, das normas, das práticas e dos saberes que dão forma a vida escolar. Fruto da ação recíproca entre o sujeito e a instituição, esse processo, como tal, é heterogêneo (Dayrell, 1996 apud GUSMÃO, 2003, p. 95).

A escola organiza os processos de compreensão da realidade e transfere ao indivíduo, de modo que, as experiências e vivências do aluno, não são tratadas e discutidas, e isto, tornando 0 atual ensino, um redutor de culturas (Iturra, 1990 apud GUSMÃO, 2003, p. 95). "[...] Educação seria tudo que se transmite, de qualquer maneira, formal ou informalmente [...], e o ensino seria a particularização da educação [...], com o objetivo exclusivo de treinar uma competência particular" (Santos, 1987 apud GUSMÃO, 2003, p. 96).

A pluralidade cultural dos grupos étnicos, sociais ou culturais, necessita ser pensada como matéria prima da aprendizagem, e nunca como conteúdo de dias especiais, datas comemorativas e determinados momentos em sala de aula. Fazer isto é congelar a cultura, reificá-la, transformá-la em curso de folclorização, e como tal, acentuar as diferenças (Iturra, 1990 apud GUSMÃO, 2003, p. 95).

O ensino nas escolas tem sido apenas uma transferência de informações prontas. Não se aplica mais o raciocínio e a discussão do mundo, para entendê-lo. "[...] Os que ensinam preocupam-se em, utilizando a escola e sua organização num dado tempo, treinar seus alunos para competências especificas: somar, dividir, contar, ler, escrever [...]" (GUSMÃO, 2003, p. 96). 
O maior desafio da educação é compreendê-la como processo de aprendizagem, baseado na comunicação e na troca permanente entre diferentes (GUSMÃO, 2003, p. 97 apud QUINTEIRO, 2000, p.31). Infelizmente, no contato pessoal com a educação escolar, sabemos que este desafio não tem sido ultrapassado, e que, em sua maioria, os alunos são treinados a decorar determinado conteúdo apenas para obter uma nota escolar e atingir seu objetivo, que é "passar de ano". Mas, o que ele tem realmente aprendido em todo esse tempo?

É comum vermos alunos questionando sobre a importância de determinado conteúdo, como - "Onde vou usar isto na vida"? Ele segue ano após ano, sem achar o real significado daquele conteúdo entendido. Por ser uma informação pronta, que não foi construída, dificilmente, assimilará e aprenderá para a vida. $O$ insucesso escolar de muitos alunos baseia-se no fato de não encontrarem as respostas que almejam conhecer no mundo; em apenas ideias decoradas que hoje são fontes de inspiração para a transposição do saber (GUSMÃO, 2003, p. 100).

Os problemas pedagógicos postos pela diversidade, ou a insensibilidade de lidar com ela, são decorrentes das referências culturais múltiplas e a do status socioeconômico de crianças e jovens que chegam à escola pública com sede de conhecer e acabam se decepcionando como 0 método de ensino, tonando-se candidatos potenciais ao insucesso escolar.

Nesse contexto, a escola tem de e deve assumir um papel de agente transformador, promovendo o conhecimento mútuo entre os diferentes, formando professores e quadros teóricos, entre muitos outros pontos [...] (Dayrell, 1996 apud GUSMÃO, 2003, p. 101).

Não é uma tarefa fácil modificar a realidade do ensino contemporâneo, e, com tamanha pluralidade cultural, o professor tem que ir muito além das práticas de ensino até aqui aprendidas. A visão de autoridade e detentor do conhecimento não ajuda neste processo. É necessário reconhecer-se neste contexto para mudar suas práticas de ensino e romper seus próprios preconceitos.

Como diz Gusmão, (2003):

Isso exige uma abertura para pensar o que somos e 0 que não somos, reconhecer o mundo do outro no nosso mundo, a vida do outro como parte da nossa vida e estabelecer pontes, abrir portas, para que o trânsito no espaço comum seja solidário e democrático. Vale dizer, sem transformar o outro num igual sem face, mas admitir sua igualdade - de direitos, de cidadania ou que mais seja -, preservando-lhe a diferença (GUSMÃO, 2003, p. 102).

Tanto a casa quanto a escola se distanciam das respostas que as crianças necessitam, 0 que coloca os adultos em seu insucesso, quanto à recomendação de "[...] amar nossas crianças 
de forma a inseri-las em nosso mundo, mas com o cuidado de preservar seu espaço de criação, de instituinte, para além do que deseja ou espera este mundo (ARENDT, 1997 apud TUMA, 2003, p. 173).

Como bem menciona Tuma, no capítulo "Palavras de professores", a maioria tem uma visão equivocada sobre o saber e não estão educando as crianças para descobertas (TUMA, 2003, p. 166). É uma realidade que abrange a escola atual, e nos faz rever nossos conceitos e práticas abordadas até aqui. Como transformar então, a realidade da crise da educação escolar? Dentre as diversas hipóteses a serem estudadas, acreditamos que a formação do professor deve estar inserida, já que a maioria não está preparada para lidar com tamanha crise e romper as barreiras do preconceito cultural.

\section{Políticas Educacionais e diversidade social no Brasil atual}

As sociedades contemporâneas e consequentemente as comunidades educativas deparam-se hoje em dia com amplos desafios, alguns dos quais decorrentes da diversidade e da heterogeneidade dos diferentes contextos aos quais é necessário responder adequadamente. Assim sendo, "é importante refletir sobre esta(s) nova(s) realidade(s) e investigar sobre as suas caraterísticas de modo a encontrar respostas adequadas aos desafios que esta diversidade nos coloca e exige" (MATA, et al, 2015, p. 1).

Para entender a questão é necessário interrogá-la e, assim, cabe a preocupação com os espaços de percepção do que venha a ser a "questão étnico-racial", a questão de gênero, e toda sorte de percalços que rondam as relações pessoais e humanas, sobretudo em suas implicações no âmbito educacional. $\mathrm{O}$ fato de persistir a cultura predatória, colonialista e escravocrata incrustada, sobretudo, nas mentes dominantes, impediu que o sentimento nacional brasileiro dedicasse atenção à questão em debate (REZENDE FILHO, 2017). Certamente, já houve muitos avanços e ainda há muito que percorrer.

O Brasil tem conquistado importantes resultados na ampliação do acesso e no exercício dos direitos, por parte de seus cidadãos. No entanto, há ainda imensos desafios a vencer, quer do ponto de vista objetivo, como a ampliação do acesso à educação básica e de nível médio, assim como do ponto de vista subjetivo, como o respeito e a valorização da diversidade. As discriminações de gênero, étnico-racial e por orientação sexual, como também a violência homofóbica, são produzidas e reproduzidas em todos os espaços da vida social brasileira. A escola, infelizmente, é um deles (GDE, 2009. P. 9). 
Todavia, a escola é um lugar onde as possibilidades de transformação são inúmeras; e, claro, muita coisa para acontecer depende não só da concepção de educação de quem está à frente da escola, mas de todos os adultos envolvidos no processo educacional. Educar não é doutrinar. Nessa perspectiva, segundo Carrara (2009) a escola precisa se preparar para poder apresentar ao aluno (a) uma reflexão que o (a) possibilite compreender as implicações éticas e políticas de distintas posições sobre o tema e construir seu olhar próprio no debate; sem, jamais, oferecer verdades absolutas.

Assim, busca-se, portanto, desenvolver uma postura crítica em relação aos processos de naturalização da diferença, embora reconheçamos que desigualdades sociais e políticas acabam sendo inscritas nos corpos: corpos de homens e mulheres, por exemplo, tornam-se diferentes por meio dos processos de socialização. Obviamente, a questão do estatuto dessas diferenças é um debate aberto e muito delicado, e a "verdade" sobre isso não deve ser encerrada em uma cartilha ou doutrina de qualquer ordem (CARRARA, 2009, p. 14).

Dessa maneira, se faz necessário ampliar o olhar dos horizontes e vislumbrar as diferentes possibilidades de compreensão e respeito à pessoa humana, independentemente de sua orientação sexual, credo religioso, cor da pele, concepção política, posição socioeconômica. Sem respeito ao outro não há avanço político, o que dificulta mais ainda a elaboração e efetivação de projetos antidiscriminatórios e de combate às desigualdades sociais e econômicas.

Precisamos, portanto, ir além da promoção de uma atitude apenas tolerante para com a diferença, o que em si já é uma grande tarefa, sem dúvida. Afinal, as sociedades fazem parte do fluxo mais geral da vida e a vida só persevera, só se renova, só resiste às forças que podem destruí-la através da produção contínua e incansável de diferenças, de infinitas variações. As sociedades também estão em fluxo contínuo, produzindo a cada geração novas ideias, novos estilos, novas identidades, novos valores e novas práticas sociais. Se projetos de gênero e diversidade na escola, por exemplo, contribuir, um pouco que seja, para a formação de uma geração que entenda o caráter vital da diferença (pelo menos de algumas delas), já terá cumprido em grande medida seu objetivo (CARRARA, 2009, p. 15).

Como diz o jargão da propaganda: "ser diferente é normal"; agora o que não se pode admitir numa sociedade democrática são as diversas formas de desigualdades, sobretudo de oportunidades. Em alusão aos avanços no reconhecimento da igualdade e da diferença contidos no PNE, assim afirmam os estudiosos Arroyo e Gomes (2017, p. 225): "avançou-se na consciência de que as desigualdades escolares tinham raízes nas desigualdades de classe, sociais, raciais, 
de gênero, orientação sexual, territoriais". Os autores lembram, ainda, que não será difícil reconhecer

que em nossa história recente, sobretudo, os grupos sociais, raciais, étnicos, culturais, discriminados porque diferentes, vem lutando pela redução das desigualdades, mas também questionam o paradigma da igualdade, não só lutando contra a discriminação, mas afirmando as diferenças e exigindo políticas de reconhecimento da diversidade (ARROYO; GOMES, 2017, p. 221).

Em relação à questão das relações étnico-raciais, Araújo (2017, p. 189) aponta que a Lei N. 10.639, de 9 de janeiro de 2003 altera a Lei no 9.394, de 20 de dezembro de 1996, que estabelece as diretrizes e bases da educação nacional, para incluir no currículo oficial da Rede de Ensino a obrigatoriedade da temática "História e Cultura Afro-Brasileira", e dá outras providências. Com relação às propostas de educação escolar indígena a Lei n ${ }^{0} 11.645$, de 10 de março de 2008 alterou

a Lei no 9.394, de 20 de dezembro de 1996, modificada pela Lei n o 10.639, de 9 de janeiro de 2003, que estabelece as diretrizes e bases da educação nacional, para incluir no currículo oficial da rede de ensino a obrigatoriedade da temática "História e Cultura Afro-Brasileira e Indígena.

É inegável que todos precisam conhecer a história africana, latino-americana, indígena; conhecer o processo histórico que discute a inserção do negro e do índio nos "projetos de nação no Brasil e em outros países da América Latina". Pereira (2015) explica que se trata de uma história da África identificada e próxima de nós, relacionada aos "processos colonialistas" caracterizados pela brutal violência, que ocasionaram revoltas de escravos, trabalhadores pobres e explorados, indígenas, ribeirinhos. Assim, faz-se necessário percorrer camada por camada de uma história "invisibilizada pela historiografia oficial". Conclui a autora acerca do processo de invisibilização do indígena: "apresentar aspectos da resistência desse grupo étnico-racial é tirar deles alguns estereótipos que lhes foram atribuídos por não terem cedido de forma dócil ao sistema de dominação colonial" (PEREIRA, 2015, p. 91-92). "Trata-se de uma luta cujo fim parece distante, mas, que para além dos fatos, há a necessidade de se interrogar o que tudo isso significa e quais são as suas condições de possibilidades" (ARAÚJO, 2017, p. 200).

Em termos de política de Estado, a diversidade é destacada como objeto de recorrência no período de redemocratização, a partir dos anos de 1980, reflete o espírito da Declaração dos Direitos Humanos de 1948. Segundo Lima (2016), não demorou a se perceber que, a partir da 
Constituição Federal de 1988, a reivindicação em si do reconhecimento das desigualdades sociais, econômicas, culturais, seria insuficiente para a construção da igualdade, ou a "igualdade de reconhecimento ao direito, por outro lado, esse primeiro olhar sobre a realidade no Brasil fora um importante indicador para se refletir a necessidade de mudanças numa sociedade antagônica como a capitalista" (LIMA, 2016, p. 28). Para o autor, as políticas educacionais são um recorte das políticas publicas que, por sua vez, são entendidas como curso de ação preferido a outros pelas autoridades postas para o enfrentamento de questões ou problemas sociais. Em termos efetivos, elas se expressam em leis, regulamentos e normas oficiais governamentais.

A diversidade, por sua vez, como temática e objeto das políticas educacionais não pode ser definida simplesmente como sinônimo do diverso, considerando os segmentos ou coletivos humanos ou ainda na conclusão de que o reconhecimento em si do multicultural resolve e harmoniza os conflitos situados historicamente. Presume sobretudo uma "[...] construção histórica, social, cultural e política das diferenças [...]" nesse sentido, os traços, identidade, relações, condicionantes e condicionamentos dos sujeitos sociais são distintos e transversalizados por complexas relações sociais de poder. Assim, a problematização sobre a necessidade da igualdade, as denúncias sobre as desigualdades sociais e o direito à diferença devem ser pauta e prática democrática de uma sociedade que procura romper com a perversidade e injustiça social (CONAE, 2014, p. 28). Nesse sentido como ponto inicial, o reconhecimento do direito à igualdade e a defesa da diferença são pontos necessários, mas solicita medidas que possam ampliar e serem difundidas como expressões do direito, fundamentadas na gestão democrática (LIMA, 2016, p. 32).

O autor lembra, porém, que isso não quer dizer que os movimentos que primam pela totalidade do atendimento aos direitos demandados, sejam, de fato, atendidos. Do ponto de vista histórico, Romanelli (2013) explica que a luta pela escola tem assumido um caráter de luta de classe.

Na verdade, a forma como se expressou e se tem expressado a demanda social de educação, forçando o sistema educacional a abrir suas portas às camadas mais baixas da população, tomou o aspecto de uma luta inconsciente, mas decisiva, das camadas em ascensão por posições de maior relevo. Aliás, consideramos que esse é um dos aspectos da expansão do ensino que explicam por que o mesmo não se modificou estruturalmente com a expansão e permaneceu oferecendo em escala maior o mesmo tipo de educação aristocrática e acadêmica da velha ordem, anterior a 1930 (ROMANELLI, 2013, p. 106). 
Assim, a discriminação social se concretiza no sistema de ensino. Mas isso não é exclusividade do Brasil. Por exemplo, Romanelli traz alguns dados franceses importantes para lermos a título de exemplo:

os agricultores que participam de $11,2 \%$ da população total têm $6,1 \%$ de sua classe representada no corpo discente das universidades. Os donos de indústria e do comércio, que representam $9,8 \%$, participam com $11,8 \%$ nesse mesmo corpo discente. Os quadros superiores, que constituem $7 \%$, contribuem com $30,2 \%$ para a população universitária. Os quadros médios, que consistem em $11,1 \%$ da população total, estão presentes com $14,9 \%$ e, finalmente, os operários, que constituem $44,9 \%$ da população têm apenas $11 \%$ de representação do alunado universitário (ROMANELLI, 2013, p. 109).

No Brasil, lembra a autora, a situação é bem mais grave, pois os lavradores praticamente não têm filhos em escola superior. Quando muito, geralmente, frequentam a escola primária. $E$ assim como acontece com os filhos dos lavradores, acontece também com os negros e pobres em geral, sejam das periferias das grandes cidades ou de cidades do interior.

De acordo com Lungarzo (2012), o Brasil é citado como exemplo de miscigenação e tolerância racial; isso vale para a grande maioria da população, escreve o autor, mas não para a ínfima minoria formada pela classe alta e média alta, com forte identidade branca e cristã de olhos voltados para a Europa. $O$ autor acrescenta que mais característica ainda é a burguesia paulista, em um estado que capricha na reprodução caricata do capitalismo estadunidense.

Grande parte (em alguns casos, a maioria) da classe alta e média e média alta, de São Paulo defende a tortura, a pena de morte, os massacres policiais em favelas e a 'faxina' contra crianças marginais. Evidencia racismo e preconceito de todo tipo, pretende proibir o acesso de negros às grandes universidades, simpatiza com o bullyng, atividade em que sua maior universidade é centro de excelência, e vota por políticos do Opus Dei. O estado já alojou a Febem, uma das prisões para menores mais truculentas do planeta. Os sucessivos governadores têm ordenado ou tolerado chacinas de pobres, afro-brasileiros e detentos desarmados, configurando o segundo maior caso de massacres num país ocidental desde 1945 (LUNGARZO, 2012, p. 256).

É possível dizer, ainda, que da mesma forma que o Estado de São Paulo se apropriou do excedente produzido por outros estados Brasil afora, e saiu à frente nos auspícios da modernidade, também dispara uma enorme carga político-ideológica educacional, sobretudo pelo poder da mídia que se concentra na região.

Felizmente, ainda que aos "trancos e barrancos", o Brasil vem se descobrindo e, com isso, vislumbra novas possibilidades de lutas e constituição nacional. E, apesar das contradições, as 
conquistas vão se concretizando, como se vê com o segundo PNE (2014-2024), suscitado das discussões das CONAES $(2010,2014)$ e demais fóruns, por meio de sua aprovação (Lei n 13.005 , de 25 de junho de 2014) que, dentre outras, em seu artigo $2^{\circ}$, a necessidade de "III - superação das desigualdades educacionais, com ênfase na promoção da cidadania e na erradicação de todas as formas de discriminação."; outro ponto no mesmo artigo: "X - promoção dos princípios do respeito aos direitos humanos, à diversidade e à sustentabilidade socioambiental." Segundo Lima (2016, p. 37) "Dentre suas 20 metas, podemos destacar um grupo de metas que trata especificamente da redução das desigualdades e valorização da diversidade, por meio da inclusão e centralidade no atendimento às suas especificidades nas políticas públicas de educação", como podemos ver na íntegra as indicações do autor:

\footnotetext{
Meta 4: universalizar, para a população de 4 (quatro) a 17 (dezessete) anos com deficiência, transtornos globais do desenvolvimento e altas habilidades ou superdotação, o acesso à educação básica e ao atendimento educacional especializado, preferencialmente na rede regular de ensino, com a garantia de sistema educacional inclusivo, de salas de recursos multifuncionais, classes, escolas ou serviços especializados, públicos ou conveniados.

Meta 8: elevar a escolaridade média da população de 18 (dezoito) a 29 (vinte e nove) anos, de modo a alcançar, no mínimo, 12 (doze) anos de estudo no último ano de vigência deste plano, para as populações do campo, da região de menor escolaridade no País e dos $25 \%$ (vinte e cinco por cento) mais pobres, e igualar a escolaridade média entre negros e não negros declarados à Fundação Instituto Brasileiro de Geografia e Estatística - IBGE.
}

Mas, enfim, diante do exposto cabe, aqui, questionar o que significa "uma escola voltada para a diversidade?" Como compreender a questão a partir dos trâmites da sociedade capitalistas? Tudo indica que a discussão é bem mais profunda! $E$, de acordo com os limites deste trabalho, não há dúvida de que se trata de um estudo que merece continuação, conforme projeto inicial.

\section{Considerações finais}

Os avanços relacionados à educação são inegavelmente visíveis. Contudo, esses avanços coexistem com questões que, em tese, já deveriam ter sido superadas. Assim, é importante promover e compreender a educação como direito fundamental e estratégia para a inclusão de saberes diversos e enfrentamento da discriminação e do preconceito, como apregoa a "educação para a diversidade".

É importante desenvolver ações que evidencie o respeito à diversidade e que tratem com deferência a todos - independente de orientação sexual, gênero, religião, idade, cor ou qualquer 
característica que evidencie a diferença entre as pessoas; importa, pois, combater quaisquer práticas e possibilidades de exclusão.

A diversidade contemporânea apresenta problemas de uma sociedade em crise cuja manifestação acontece em vários espaços sociais, inclusive na escola. Ocorre que a crise na escola é precedida por uma crise na educação que, por sua vez, decorre de uma crise da sociedade, ou, se quiser, da crise da sociedade capitalista.

Não se trata, porém, de uma mera crise moral ou de autoridade. Contudo, conforme sinalizou Arendt (2007), essa crise oportuniza refletir e discutir paradigmas. Para tanto, é necessário muito estudo e pesquisas na mesma proporção (ou maior) da complexidade demandada.

As questões relativas à diversidade e educação estão relacionadas às políticas educacionais. Em sendo assim, a busca pela resolução do problema se tornaria inviável por fora da política. Dessa maneira, continuaremos este estudo certos de que não basta analisar a crise na educação ou na escola apenas com parâmetros relacionados à diversidade em si. É necessário ir além, e compreender a dinâmica da escola e da diversidade no âmbito da crise do atual modelo de sociedade, sob a égide do Capital.

\section{REFERÊNCIAS}

ARAÚJO, Adelmar Santos de. Heranças da escravidão e questão das relações étnico-raciais no Brasil. In:___ (Org.). A questão das relações étnico-raciais no Brasil: olhares reflexivos. Goiânia: Editora Kelps, 2017, p.189-202.

ARENDT, Hanna. Entre o passado e o futuro. 5 ed., São Paulo: Perspectiva, 2007.

ARROYO, Miguel G.; GOMES, Nilma Lino. Possibilidades e limites para entender a relação entre PNE e diversidade em tempos de retrocessos: questões pendentes. In: DOURADO, Luiz Fernandes (Org.). Plano Nacional de Educação: PNE: 2014/2024: avaliação e perspectivas, Campinas-SP: Mercado de Letras, 2017, p. 217-257).

BRASIL, Lei n⿳ 10639, de 9 de janeiro de 2003. Altera a Lei no 9.394, de 20 de dezembro de 1996, que estabelece as diretrizes e bases da educação nacional, para incluir no currículo oficial da Rede de Ensino a obrigatoriedade da temática "História e Cultura Afro-Brasileira", e dá outras providências. Diário Oficial [da] República Federativa do Brasil. Brasília, DF, 9 jan. 2003. Disponível em: http://www.planalto.gov.br/ccivil_03/leis/2003/L10.639.htm . Acesso em 10/06/2016.

BRASIL, Lei $n^{0}$ 11. 645, de 10 de março de 2008. Altera a Lei no 9.394, de 20 de dezembro de 1996, modificada pela Lei no 10.639 , de 9 de janeiro de 2003, que estabelece as diretrizes e 
bases da educação nacional, para incluir no currículo oficial da rede de ensino a obrigatoriedade da temática "História e Cultura Afro-Brasileira e Indígena".

CARRARA, Sérgio. Educação, diferença, diversidade e desigualdade. In: GÊNERO E DIVERSIDADE NA ESCOLA: formação de professoras/es em Gênero, orientação Sexual e Relações Étnico-Raciais. Livro de conteúdo. versão 2009. - Rio de Janeiro: CEPESC; Brasília: SPM, 2009. Disponível em:

http://estatico.cnpq.br/portal/premios/2014/ig/pdf/genero_diversidade_escola_2009.pdf. Acesso em 14 de julho de 2018.

GÊNERO E DIVERSIDADE NA ESCOLA: formação de professoras/es em Gênero, orientação Sexual e Relações Étnico-Raciais. Livro de conteúdo. versão 2009. - Rio de Janeiro: CEPESC; Brasília: SPM, 2009. Disponível em:

http://estatico.cnpq.br/portal/premios/2014/ig/pdf/genero_diversidade_escola_2009.pdf. Acesso em 14 de julho de 2018.

GUSMÃO, Neusa Maria Mendes de. Antropologia e educação: origens de um diálogo.

Disponivel em: http://www.scielo.br/scielo.php?script=sci_arttext\&pid=S0101-

32621997000200002. Acesso em 07/07/2019.

GUSMÃO, Neusa Maria Mendes de. Antropologia, diversidade e educação: um campo de possibilidades. Revista ponto-e-vírgula, 10: 32-45, 2011. Disponível em:

https://revistas.pucsp.br/index.php/pontoevirgula/article/view/13898/10222. Acesso em 30 de julho de 2018.

LIMA, Paulo Gomes. A diversidade nas políticas educacionais no Brasil. Cad. Pes., São Luís, v. 23, n. Especial, set./dez. 2016. Disponível em:

http://www.periodicoseletronicos.ufma.br/index.php/cadernosdepesquisa/article/view/6198/3742. Acesso em 07/07/2018.

LUNGARZO, Carlos A.. Os cenários ocultos do caso Basttiti; com entrevista exclusiva de Cesare Battisti. São Paulo: Geração Editora, 2012.

MATA, Lourdes et al (Org.). Diversidade e educação: desafios atuais. Lisboa: ISPA - Instituto Universitário, 2015.disponível em:

http://repositorio.ispa.pt/bitstream/10400.12/5183/1/ACIPE_JUN-2015.pdf. Acesso em 4 de julho de 2018.

ROMANELLI, Otaíza Oliveira. História da educação no Brasil, 39 ed., Petrópolis-RJ: Editora Vozes, 2013.

VALENTE, Ana Lúcia E. F. Parte I - Conhecimentos antropológicos nos parâmetros curriculares nacionais: para uma discussão sobre a pluralidade cultural. In: GUSMÃO, Neusa Maria Mendes de. Diversidade Cultura e Educação: Olhares cruzados. Editora Biruta. São Paulo, abril de 2003. 